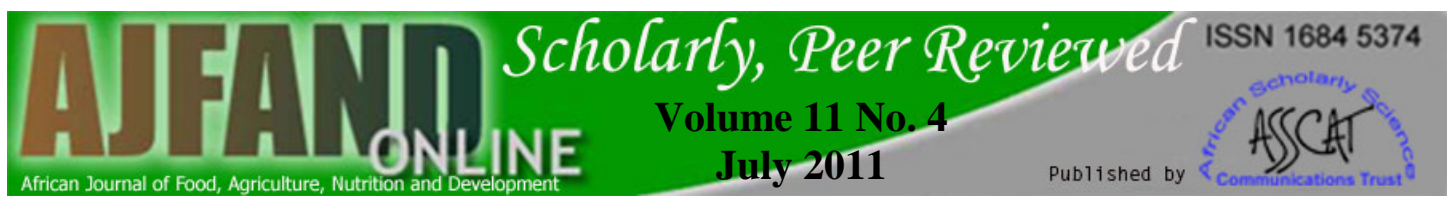

\title{
NUTRITIONAL QUALITY OF THE LUNCHES OF CHILDREN IN DAY CARE IN OSUN STATE OF NIGERIA
}

\section{Ogbimi GE ${ }^{1}$ and BO Ogunba ${ }^{1^{*}}$}
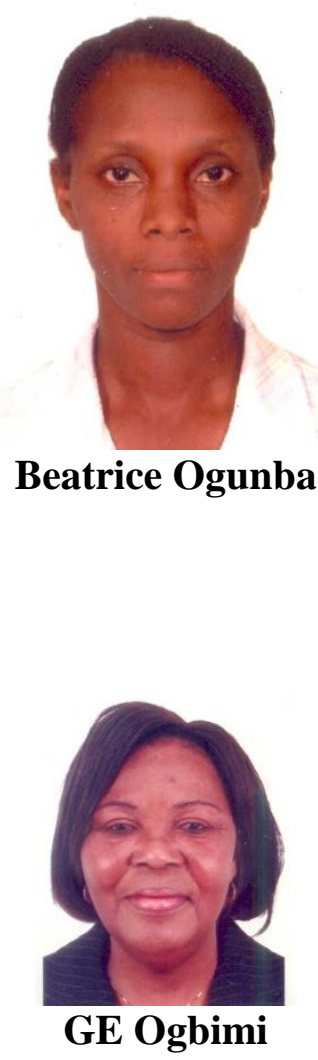

*Corresponding author email: ogunbabeatrice@yahoo.com

${ }^{1}$ Department of Family, Nutrition and Consumer Sciences, Faculty of Agriculture, Obafemi Awolowo University, Ile Ife, Nigeria 


\section{ABSTRACT}

Food patterns and dietary quality in the early years of life are usually determined by parents and other primary caretakers. Unfortunately the diets commonly offered to young children are of low quality and often lack variety, which is the key to specific nutrient adequacy. They are usually of low energy and nutrient density and as a result, multiple nutrient deficiencies are common in this age group. This study investigated the nutritional quality of the lunches of children in day care in Osun State of Nigeria. A structured interview schedule was used to collect data from 180 mothers randomly selected from the study area. Mothers were interviewed about their children's eating habits, lunches and snacks packed for school. Descriptive statistics, such as percentages and frequency, were used to describe data. The results of the study revealed that $76 \%$ of the children ate breakfast before going to school. Almost all (91\%) mothers gave their children lunch packs for school. The majority (72\%) of the children went to school with additional mid-morning snacks, such as biscuits and pastries, and $12 \%$ took fruits. Few children (16\%) did not take snacks to school. The socio-economic status of mothers was also considered and its effect on type of meal packed was examined. Results showed that $44.4 \%$ of the meals packed by mothers included carbohydrate-rich foods; 33.3\% were partially balanced diets; and 22.3\% packed a balanced meal for the children. Lower class mothers (15\%) gave carbohydrate-rich food, while those of the middle class (21\%) gave partially balanced diets. The percentage of mothers that packed balanced meals was not significantly different for the three socio-economic groups. It is recommended that mothers should have access to nutrition information about recommended dietary practices for children and should be educated on how to use the four food plan group in planning meals for children through nutrition education programmes.

Key words: malnutrition, preschool, adequate diet, lunches 


\section{BACKGROUND}

The second year of life is a time of transition from infancy to childhood. Internal organs continue to mature, growth slows, activity increases, eating skills improve and nutritional needs become similar to those of older children. The early time of life has been recognized as being a particularly critical time for developing good dietary patterns, and for providing the nutrients in the amounts required for optimum growth and development during this critical period of growth.

The average preschool child needs to eat every four to six hours to maintain a blood glucose concentration high enough to support the activities of the brain and nervous system since the brain is the body's chief glucose consumer [1, 2]. Healthy eating habits among children play a key role in their mental and physical development and also promote growth and reduce many risks associated with both immediate and longterm health problems [3, 4].

Appropriate nutrition is a basic human need that remains unmet for a vast number of children; the trend of malnutrition in sub-Saharan Africa is disturbing. For the region as a whole, no progress has been made in reducing the prevalence of child malnutrition over the past 15 years, and there are some indications that the situation has worsened. Ethiopia and Nigeria are countries in the Sub-Saharan Africa with the very high rate of malnutrition. [5, 6]. Preschool children are often undernourished, with positive clinical signs of low weight-for -height and thin subcutaneous fat. Hence, the provision of lunch with adequate nutrients in day-care could be considered an important factor in enhancing nutrient intake of preschool children [7].

\section{Impact of Mothers' Work on Nutritional needs of preschool children}

Urban poverty in sub-Saharan African countries including Nigeria has contributed to a high proportion of women participating in the labour force. In order to meet the financial needs of family, mothers spend long hours daily working outside the home $[8,9]$. As a result, mothers have little or no time to prepare quality lunches for their children. Also, the present economic crises in Nigeria had contributed adversely to the cost of living. With too little income that most families depend on, they tend to prepare food of low nutritional value for their children regardless of what they might know as essential food for good health and growth.

While mothers are away at their different places of work, a variety of alternative care systems are available. These include institutional day care, nursery schools, home day care, informal arrangements with family members or paid caregivers in the home. During the eight hours spent in day care, a meal is expected to be provided through government-sponsored school lunch programmes. The prevalent situation in Nigeria is that children in the day care are not fed because there is no financial support from the government or NGOs to operators to provide lunch for the children. It is the responsibility of the parents to provide food and snacks. All foods that are carried from the home are prepared by parents, mostly mothers, and hopefully these are varied and nutritious. The foods should be packed under proper hygienic conditions to prevent contamination. There is need for parents, especially mothers, to have a little 


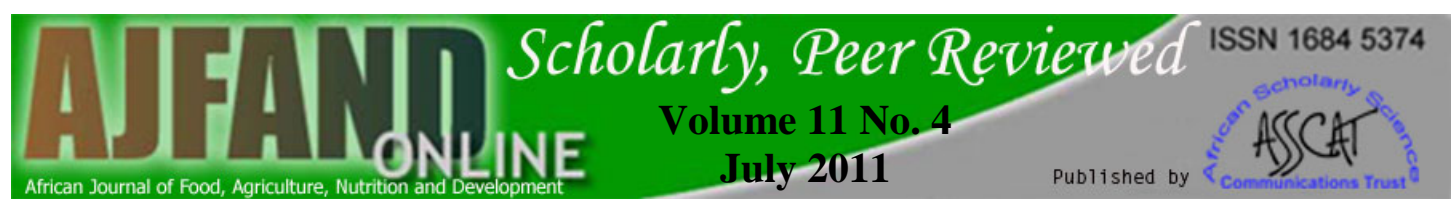

forethought and plan wisely to include foods from the Basic Four Food Plan, which is defined in this study as 1) milk and milk products, 2) meat and meat alternatives, 3) fruits and vegetables, and 4) bread and cereals. They should also understand children's food preferences in terms of appearance, taste, texture, and temperature of food [10].

Parents usually pack any available food and snack for their children irrespective of their nutritional adequacy. The reason for this practice could be lack of mothers' awareness of the nutritional needs of their preschool children. The main objective of the study, therefore, was to investigate the nutritional quality of the lunches of children in day care in Osun State of Nigeria.

The specific objectives are to:

i) investigate the feeding habits of children

ii) identify the type of lunch packed for preschool children

iii) determine the relationship between child feeding and socio economic status of mothers

\section{METHODOLOGY}

In order to obtain information on the lunches packed for children in day care. A study was carried out in seven randomly selected out of forty two daycare centres within Ife Central Local Government Area of Osun State. A simple random sampling technique was used to select one hundred and eighty respondents involved in the study from 73670 mothers. Information was obtained from mothers whose preschoolers were in the selected daycare. This was done through the use of structured interview schedule. Snacks and lunches packed for children were observed and recorded through participatory observation technique. A 24-hour recall of the food the respondents prepared for the preschoolers was carried out to assess their nutritional knowledge and application of the Basic Four Food groups in the preparation of family daily meals. A 24-hour food intake recall containing fruits, green leafy vegetables, and cereal products were categorized as a balanced diet' one or two of the groups lacking was categorized as a partially balanced diet, while meals containing mainly complex carbohydrates and simple sugars were categorized as carbohydrate-rich foods. Finally, the mother's years of formal education and occupation were the indicators used to determine the socio-economic status of the child's family.

\section{RESULTS}

\section{Baseline Characteristics}

The age range of the children was 2-6 years with a mean age of 4.2 years. The majority of the children were $4-5$ years $(40.0 \%)$, followed by 5 - 6 years $(37.2 \%)$ and 2-3 years (22.8\%). As presented in Table $1,35.6 \%$ had $1-3$ children, $34.4 \%$ had $4-7$, and $30 \%$ had 7-9. All respondents had some form of education: $11.1 \%$ secondary school certificate, 66.7\% with either OND- Ordinary National Diploma/NCE National Certificate of Education/HND - Higher National Diploma, and 22.2\% with a University degree. As presented in Table 1, 38.8\% were petty traders, $22.4 \%$ were

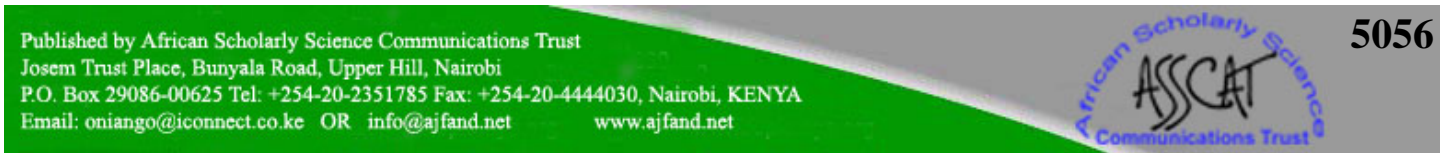




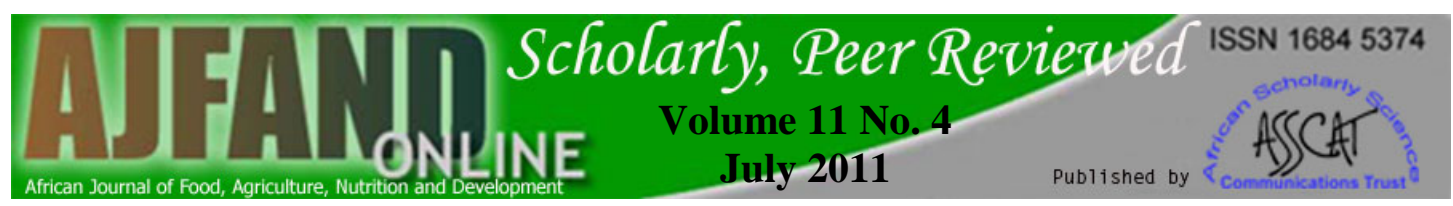

civil servants/teachers, and 38.8\% were professionals, such as medical doctors and bankers.

\section{Children's eating habits}

As seen in Table 2, 76\% of the children ate breakfast before going to school while $24 \%$ did not. Some of the children, however, went to school with a mid-morning snack while some took only their lunch packs. The majority (80\%) had meals in their lunch packs, while $11 \%$ go had biscuits and pastry, and $9 \%$ do not take lunch packs. The majority (72\%) took biscuits and pastry to school as a midmorning snack, $12 \%$ took fruits, while $16 \%$ of the children were not given any snack.

\section{Category of food provided from 24-hour recall}

From the results of the 24-hour food recall, the respondents prepared meals for their preschoolers where $23.3 \%$ contained fruits, green leafy vegetables, and cereal products (balanced diet), 33.3\% was a partially balanced diet, and $44.4 \%$ contained mainly complex carbohydrates and simple sugars, which was categorized as a carbohydrate-rich diet.

\section{Feeding habit and socioeconomic status of mothers}

The socioeconomic status of mothers with respect to their occupation and education was taken into consideration in determining their application of the Basic Four Food plan in meeting the nutritional needs of the family.

The results in Fig. 1 revealed that mothers from all the socio-economic groups fed their family with either carbohydrate-rich, partially balanced, or a balanced diet. Mothers from the middle class fed mainly a partially balanced or balanced diet to their children. However, mothers from the lower class fed their family with more carbohydrate-rich foods. 

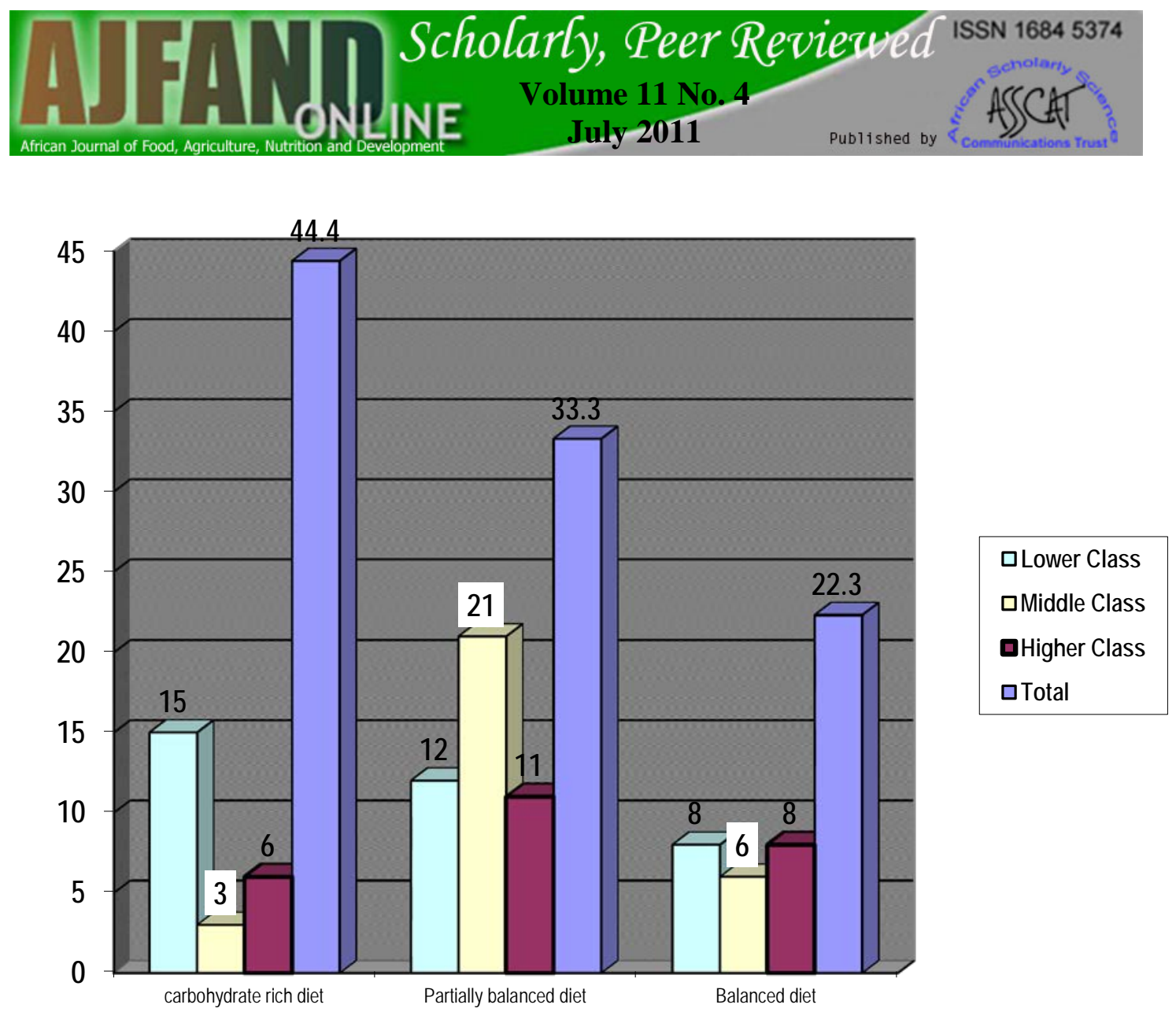

\section{Figure 1: Distribution of children's food consumption and socio-economic status of parents}

\section{DISCUSSION}

From the results obtained, one third of the children had no breakfast before going to school.Some children took their food to school,and some took only snacks such as fruits and pastries. Although it is recommended that children should take a snack in order to meet their nutritional requirements, snacks are not to replace children's meals.

Parents were primarily responsible for their child nutrition. The social environment, including various socio-economic and socio-cultural factors, such as parents' education, time constraints, and ethnicity, influence the types of foods children eat [11].The family environment has a tremendous influence on a child's development, eating and activity habits, and predisposition to being overweight[12,13,14].Children's eating behaviours are influenced by the family food environment, including parental food preferences and beliefs; children's food exposure; role modeling; media exposure; and child-parent interactions around foods[14, 15,16]. The nutrient quality of the diets of 3-to 5-year old children is influenced by the eating patterns of their parents[17]. This is seen in the study area where mothers pack carbohydrate-rich foods for children showing the food choices and habits of the households. This could be due to a lack of knowledge of mothers on 


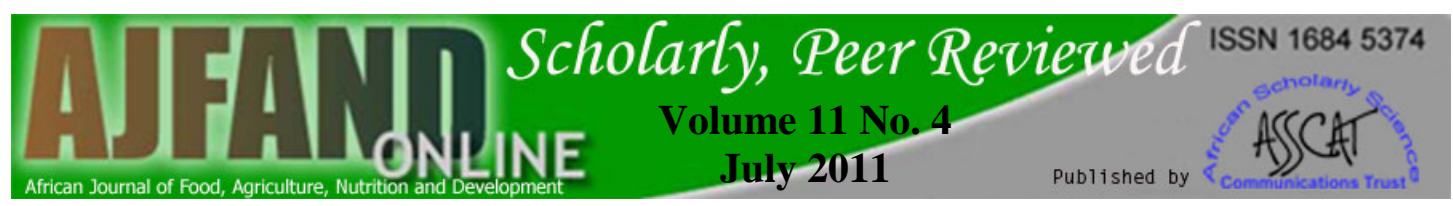

the combination of food that are beneficial to child growth, and financial resource constraints [18].

Children as they grow older have increasing needs for all nutrients. It is suggested that consumption of a varied diet reduces the risk of developing a deficiency or excess of anyone nutrient [19]; it may, therefore, somehow be associated with the dietary nutrient quality. The nutrients essential for meeting nutritional requirements are not all usually found in a single food item; they are, however, present in a diet composed of a number of foods [20]. It is therefore important that children eat a variety of food to meet their nutritional requirements. A recent review of childhood diets in subSaharan Africa illustrated how limited variety in a young child's diet significantly reduces nutritional status and contributes to retarded growth [21]. Poor-quality diets lacking variety and palatability can influence appetite, leading to poor consumption patterns in young children and diminished growth [21, 22]. There is a need for a total diet approach that encourages the consumption of fruits, vegetables, and grains, with an emphasis on lower-fat options [23].Parents are expected to pack snack/lunches for their children to bring to school. It is, however, important that it be well-prepared and appetizing enough to appeal to the taste of the child.

Women's education and social status play a role in household food security and the household decisions made in these areas are influenced by women's knowledge regarding the nutritional benefits of different foods. The results emphasized the fact that the carbohydrate/sugar rich snacks/lunches packed for the children was more than a poverty issue but a combination of poverty and lack of good nutritional knowledge.

None of the daycare studied has a feeding programme for the children in attendance. Feeding programmes can help in the solution of both macro- and micronutrient deficiencies in children and attendant infection and diseases. Malnutrition in the preschool years leads to stunting, wasting and underweight, and these have been widely observed to be associated with reduced school performance [24].

\section{CONCLUSION AND RECOMMENDATIONS}

The women in the study seem to have little or no knowledge of the importance and the application of the Basic Four-Food plan in the preparation of nutritious snacks/lunches and diets for preschoolers and other family members. This was revealed in the rich carbohydrates and sugar-snacks and lunches packed for preschool children by mothers from low, middle and high socioeconomic status involved in the study. It is not enough to simply feed a child sufficient calories to prevent hunger; it is also necessary to be sure that the diet includes an adequate amount of foods from the Basic Four Food plan.

It is, therefore, recommended that mothers should be educated and exposed to the Basic Four-Food plan, especially on how the plan can be used to combine available local foods in their communities to meet the nutritional needs of the family. 


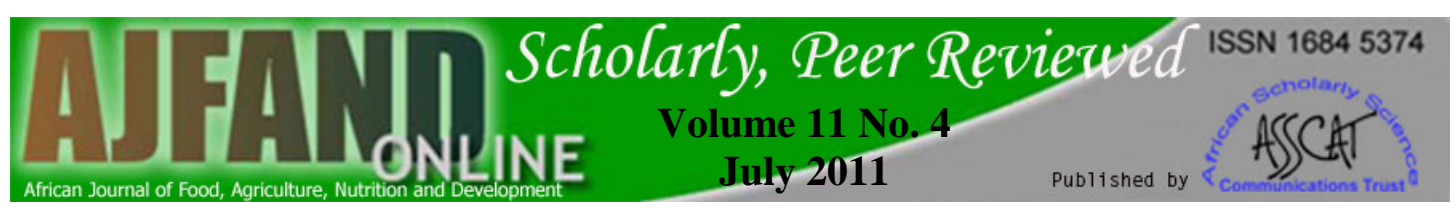

Table 1: Distribution of respondent by socio economic characteristics

\begin{tabular}{|l|l|l|}
\hline Socio Economic Status & Frequency N = 180 & Percentage \\
\hline Age of children & & \\
2-3 years & 41 & 22.8 \\
4-5 years & 72 & 40.0 \\
5-6 years & 67 & 37.2 \\
\hline Number of Children & & \\
$1-3$ & 64 & 35.6 \\
$4-7$ & 62 & 34.4 \\
$7-9$ & 54 & 30.0 \\
\hline Educational Level & & \\
Secondary School Certificate & 20 & 11.1 \\
* OND/NCE/HND & 120 & 66.7 \\
University Degree & 40 & 22.2 \\
& & \\
\hline $\begin{array}{l}\text { Occupation } \\
\text { Petty Traders, Tailors }\end{array}$ & 70 & 38.8 \\
Civil Servants/Teachers & 40 & 22.4 \\
$\begin{array}{l}\text { Professionals: } \\
\text { practitioners }\end{array}$ & 70 & 38.8 \\
\hline
\end{tabular}

*OND- Ordinary National Diploma

CE - National Certificate of Education

HND - Higher National Diploma 


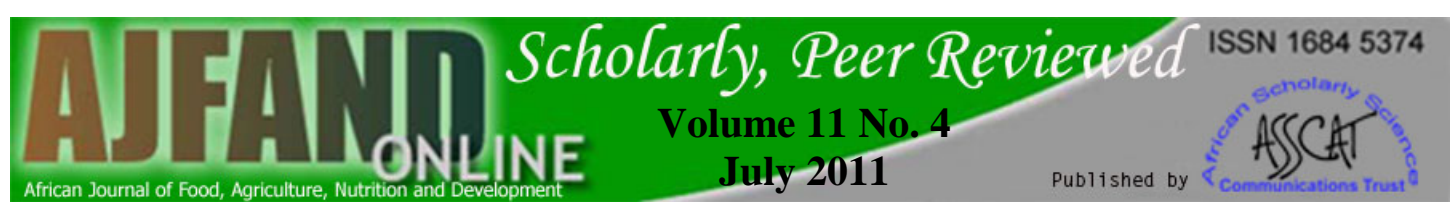

Table 2: Frequency Distribution of Children's Eating Habits

\begin{tabular}{|l|l|l|}
\hline Variables & Frequency & \% \\
\hline 1. Breakfast: & & \\
Eaten before going to school & 136 & 76 \\
Do not eat before going to school & 44 & 24 \\
2. Mid-Morning snack & & \\
Biscuits/pastry & 130 & 72 \\
Fruits & 22 & 12 \\
No snack & 28 & 16 \\
& & \\
3. What parent pack as lunch & 20 & 11.0 \\
Snack & 144 & 80.0 \\
Food & 16 & 9.0 \\
No lunch & & \\
4. Category of food provided & & \\
from 24 hour recall & 40 & 23.3 \\
$\quad$ Balanced diet & 60 & 44.4 \\
$\quad$ Partially balanced & 80 & \\
Carbohydrate- rich food &
\end{tabular}




\section{REFERENCES}

1. Guthrie HA Introductory Nutrition $5^{\text {th }}$ edition, 1986. The C.V. Mosby Company.

2. Whitney EN, Cataldo CB and SR Rolfes Understanding normal and clinical Nutrition $3^{\text {rd }}$ edition, West Publishing Company 1991.

3. Bordi PL, Park JE, Watkins S, Caldwell D and CA DeVitis Impact of the environment on food choices and eating habit of school age children Journal of Child Nutrition and Management issues, 2002;26( 2) Fall 2002SCN. Standing Committee on Nutrition A periodic review of developments in international nutrition, 2003 Edited by Andrea D. Morereira, PS ID. Printed by the Lavenham Press, U.K.

4. SCN. Standing Committee on Nutrition A periodic review of developments in international nutrition, 2003 Edited by Andrea D. Morereira, PS ID. Printed by the Lavenham Press, U.K.

5. Getahun Z, Urga K, Ganebo T, and A Nigatu Review of the status of Malnutrition and trends in Ethiopia. Ethiopian Journal of Health Development,2001; 15:55-74.

6. Adewara SO and M Visser Use of Anthropometric Measures to Analyze How Sources of Water and Sanitation Affect Children's Health in Nigeria. Environment for Development Discussion Paper Series 2011 EfD DP 11-02

7. Smith LC, Ramakrishnan U, Ndiaye A, Haddad L and R Martorell The importance of women status for child nutrition in developing countries. IFPRI Research Report 1312003 pp 1.

8. Engle PL and L Lhotska The role of care in programmatic Actions Designing and evaluation programme involving care. Food and Nutrition Bulletin 1999;20:121-135.

9. Ogbimi GE and JA Alao "Developing sustainable day care services in rural communities of Nigeria” Early Child Development and Care, 1998; 347-58.

10. Drake MA Anthropometry, biochemical iron indexes and energy and nutrient intake of preschool children: Comparison of intake at day care centre and at home Journal of the American Dietetics Association 1991; 91:1587 - 1588.

11. Heather PP and TA Nicklas A review of family and social determinants of children's eating patterns and diet quality. Journal of the American College of Nutrition, 2005; 24(2):83-92. 
12. Fitzgibbon ML, Stolley MR and AR Dyer A community-based obesity prevention program for minority children; rationale and study design for HipHop to Health Preventive Medicine 2002; 34:289-297.

13. Campbell $\mathbf{K}$ and $\mathbf{D}$ Crawford Family food environments as determinants of preschool-aged children's eating behaviours; implications for obesity prevention policy. A Review: Australian Journal of Nutritional Dietetics2001;58:19-25.

14. Finn K, Johannsen $\mathbf{N}$ and B Specker Factors associated with physical activity in preschool children. Journal of Pediatrics 2002; 140:81-551.

15. Stockmyer C Remember when mom wanted you home for dinner? Nutrition Review 2001; 59(2):57-60.

16. Birch LL and KK Davison Family environmental factors influencing the developing behavioural controls offood intake and childhood overweight. Pediatric Clinical North America 2001; 48(4):893-907.

17. Oliverie SA, Ellison RD and LLMoore Parent-child relationships in nutrient intake; the Framingham Children's Study. American Journal of Clinical Nutrition 1992;56(3):593-8.

18. Jyoti DF, Frongillo EA and SJ Jones Food insecurity affects school children's academic performance, weight gain, and social skills Nutrition2005;135:28312839..

19. Krebs-Smith SM, Smiciklas-Wright H, Guthrie HA and J Krebs-Smith The effects of variety in food choices on dietary quality. Journal of the American Dietetics Association 1987; 87 :897 -903.

20. Hsu-Hage BH and ML Wahlqvist: Food variety of adult Melbourne Chinese: a case study of a population in transition. World Review of Nutrition and Dietetics 1996; 79:53 -69.

21. Onyango AW Dietary diversity, child nutrition and health in contemporary African communities. Comparative Biochemistry and Physiology. 2003; 136:6169.

22. Lutter CK and JA Rivera Nutritional status of infants and young children and characteristics of their diets. Journal of Nutrition. 2003;133: 2941S-2949S.

23. American Dietetic Association: Dietary guidance for healthy children aged 2 to 11 years - Position of ADA. Journal of American Dietetic Association. 1999; 99:93-101.

24. Dean TJ Child malnutrition and school performance in China Journal of Development Economics1986;20(2): 299-309 